\title{
Nesnelerin İnterneti Tabanlı Kablosuz Taşınabilir EKG Cihazı
}

\author{
Bircan Çiftçi ${ }^{1 *}$, Zeynep Şen ${ }^{2}$, Mustafa Alper Akkaş ${ }^{3}$ \\ ${ }^{1 *}$ Bolu Abant İzzet Baysal Üniversitesi, Mühendislik Fakültesi, Bilgisayar Mühendisliği Bölümü, Bolu, Türkiye (ORCID: 0000-0002-2380-2175), \\ bircan.1997898@gmail.com \\ 2 Bolu Abant İzzet Baysal Üniversitesi, Mühendislik Fakültesi, Bilgisayar Mühendisliği Bölümü, Bolu, Türkiye (ORCID: 0000-0002-8319-5063), \\ zeynepsen0698@gmail.com \\ ${ }^{3}$ Bolu Abant İzzet Baysal Üniversitesi, Mühendislik Fakültesi, Bilgisayar Mühendisliği Bölümü, Bolu, Türkiye (ORCID: 0000-0003-0185-0464), \\ alperakkas@ibu.edu.tr
}

(3rd International Congress on Human-Computer Interaction, Optimization and Robotic Applications June 11-13, 2021)

(DOI: $10.31590 /$ ejosat.949795)

\begin{abstract}
ATIF/REFERENCE: Çiftçi, B., Şen, Z. \& Akkaş, M. A. (2021). Nesnelerin İnterneti Tabanlı Kablosuz Taşınabilir EKG Cihazı. Avrupa Bilim ve Teknoloji Dergisi, (26), 91-95.

$\ddot{O} \mathbf{z}$

Teknolojinin gelişmesiyle birlikte kablolu ve kablosuz olarak internet yoluyla verilerin gönderilmesi sağlanmıştır. Bu gelişmeler ile ortaya çıkan nesnelerin internetinin (NI) en önemli alanlarından biri de sağlık alanıdır. Sağlık alanındaki çalışmalar giyilebilir teknolojiyi ortaya çıkarmıştır. EKG (Elektrokardiyografi), kalp hücreleri tarafından üretilen ve kalbin çalışmasını sağlayan elektriksel aktivitenin kaydedilip analiz edilmesi işlemine denir. Hastanelerdeki mevcut EKG cihazlarında, hastalardan alınan sinyaller kablolar vasıtasıyla monitöre aktarılmaktadır. Bu çalışmada, hasta ile monitör arasında var olan kablo bağlantısını ortadan kaldırarak kablosuz bir elektrokardiyogram cihazının tasarımının yapılması amaçlanmıştır. Tasarladığımız EKG cihazı ile covid şartlarından dolayı hastaneye gidemeyen kişilerin uzaktan takibi yapılabilecek ve günlük hayatta hastaların izlenimi gerçekleştirilebilecektir. AD8232 Kalp Hızı Ölçer ve vücuda bağlanan Holter Cihazı ile alınan veriler, gözlem altındaki kişinin sağlık koşullarını analiz etmek için kullanılabilmektedir. Bu çalışmada kalp atış hızı ölçmek için Arduino mikrodenetleyicisini Android işletim sistemine sahip bir telefon ile birleştirdik. Sinyallere ulaşabilmek için AD8232 Kalp Hızı Monitörü kullanarak, HC06 bluetooth sensörü ile telefonumuza sinyalleri gönderdik. Ayrıca nabız sensörü ile Arduino arasındaki bağlantıyı gerçekleştirerek hastanın nabız ölçümünü sağladık. Çalışmanın ara yüzünü oluşturabilmek ve alınan değerleri ekranımıza yansıtabilmek için MIT App Inventor programını kullandık.
\end{abstract}

Anahtar Kelimeler: Nİ, EKG, Arduino, App Inventor, Sağlık Hizmetleri, Mobil Uygulama, Nabız.

\section{Internet of Things Based Wireless Portable ECG Device}

\begin{abstract}
With the development of technology, it has that data can via the internet sending as wired and wireless. One of the most important areas of the Internet of Things that emerged with this development is the field of health. Studies in the field of health have revealed the wearable technology. ECG (Electrocardiography) is the process of recording and analyzing the electrical activity produced by the heart cells and enabling the heart to work. In the existing ECG Devices in hospitals, the signals received from the patients are transferred to the monitor via cables. This work, patient and monitor exist between annihilate wiring purpose cordless an electrocardiogram device desing. Our desing ECG device covid conditions people who cannot go to hospital distant follow up can do and daily life patients is impression realizable. AD8232 heart rate meter and body worn Holter device is data received keep under person health conditions can use analyzation. This works heart pulse rate for gauge Arduino microcontroller defragment Android operating system. Signals to reach are able to AD8232 heart rate monitor use, HC06 bluetooth with detecting element our mobile phone send signals. In addition, we performed Arduino with the pulse sensor and provided the measurement of the received pulse. We use the MIT App Inventor Program to create the interface of the work and to reflect it on our screen.
\end{abstract}

Keywords: IoT, ECG, Arduino, MIT App Inventor, Health Services, Mobile App, Pulse.

\footnotetext{
* Sorumlu Yazar: Bolu Abant İzzet Baysal Üniversitesi, Mühendislik Fakültesi, Bilgisayar Mühendisliği Bölümü, Bolu, Türkiye (ORCID: 00000002-2380-2175), bircan.199798@gmail.com
} 


\section{Giriş}

Nİ ile insanlığın devamı için en önemli konu olan sağlık birleştirilerek güçlü çözümler ortaya çıkarılmak istenmiştir. Bunun için NI'de bulunan birçok sensörün insan ile birleşimi amaçlanmıştır. Sensörlerin taşınabilir boyutta olması konusunda çalışmalar yapılmıştır. Nİ kavramının uygulama alanlarında olan giyilebilir teknoloji ile sağlık sektörü bir araya getirilmiştir (Akleylek, Kılıç, Söylemez, Aruk ve Aksaç, 2020). Giyilebilir teknoloji sayesinde kişi günlük yaşamında sorun yaşamadan, hareket kısıtlaması olmadan tıbbi verilerin uzun süreli kayıt altına alınması, bu verilerin bir sunucuya aktarılması ve acil durumlarda uyarı verilerek ilgili kurumların harekete geçirilmesi sağlanmıştır (İlhan, 2016). Kablosuz haberleşme teknolojisi ile uzaktan sağlık izleme ve tele-tıp konusunu ve giyilebilir uzaktan sağlık izleme sistemlerinin gelişmesini sağlamıştır (Binkley, 2003).

Dünyada kalp rahatsızlığı yüzünden binlerce insan hayatını kaybetmektedir. Avrupa ülkeleri arasında ülkemiz ilk sırada yer almaktadir (Arslan ve Tankut, 2018). Kalp ve damar hastalıklarının sigara, hipertansiyon, kan yağları, aileden gelen kalıtsal kalp rahatsızlığ bağlı olarak ortaya çıktığı bilinmektedir. $\mathrm{Bu}$ rahatsızlıkların beraberinde getirdiği ölüm oranlarını azaltmak için Elektro Kardiyograf cihazı yapılmıştır. $\mathrm{Bu}$ cihaz ile kalpte oluşan elektriksel aktiviteler gözlemlenmektedir ve alınan veriler ile kalpte görülen hastalıklar önceden tespit edilip gerekli önlemler alınabilmektedir. EKG cihazı ile kalbin akış hızı ve nabzı kolay bir şekilde ölçülebilmektedir. EKG cihazı sağlık ocağı, hastane gibi kurumların kalbin izlenimi ve hastalığın teşhisi için kullanılmaktadır (Kurban, 2006). Hastalıkların belirlenmesi için nabız değerlerinin ölçümü de önem taşımaktadır. Kalp krizi tanısında takibi tutulması gereken bir faktördür (Göktaş ve Yağanoğlu, 2020).

Kalp tarafindan üretilen ve beden yüzeyine iletilen elektriksel işaretler EKG holterleri ile kollara, bacaklara ve göğüs üzerindeki belli yerlere yerleştirilen elektrotlar yardımıyla oluşur (Ekmekci ve Ergün, 2017). Bu sensörlerden elde edilen veriler kaydedilir. EKG sinyali birçok kalp hastalıklarının erken teşhisinde kullanılmaktadır (Kurban, 2006). Elde edilen EKG sinyalleri Arduino UNO üzerinde bulunan Analog/Dijital çevirici ile sayısallaştırılıp, bluetooth ile cihaza gönderilmiştir (Şenyer Yapıc1, Işık ve Uzun, 2018). Bluetooth modülü (HC-06) kullanılarak donanım ile yazılım arasında bağlantı kurulmuştur. Tasarlanmış olan donanım ile insan vücudundan alınan nabız ve EKG değerleri bluetooth yardımıyla tasarlanan Android uygulamaya aktarılmıştır (Yalman, Coşkun ve Haşıloğlu, 2015).

T.K. Kho ve arkadaşları, EKG ile bluetooth teknolojisini birleştirerek izleme sistemi geliştirilmiştirler. Sistemde EKG cihazından alınan veriler bilgisayara bluetooth yoluyla gönderilmiştir ve Arduino UNO programında grafiksel olarak gösterimi sağlanmıştır. Böylece hastaların istedikleri yerde istedikleri zaman kendi kontrollerini yapabilmelerine olanak sağladığını göstermişlerdir (Kho, Besar, Tan, Tee ve Ong, 2005). S. Can, bluetooth ile EKG verilerini cep telefonuna iletilmesini sağlamıştır (Can, 2010). Benzer bir uygulama ise A. M. Nasrabadi ve M. H. Kani, vücuttan alınan EKG sinyallerini bluetooth modülü ile telefona göndermeye çalışmışlardır (Konuk, 2014). Yapılan bu çalışmada verilen bilgisayar dışında telefonda gösterimi sağlanmış, tasarlanan uygulama ile veriler doktora iletilmiştir. Kalp atım hızı kilo, yaş etmenlerine veya kalp yetmezliği, guatr gibi hastalıklara göre değişebilmektedir. $\mathrm{Bu}$ çalışmaya nabız sensörü ekleyerek birçok hastalığın tedavisi olarak EKG cihazı kullanılmıştır. Bu çalışma ile kalp hastalarına faydalı olmak, onları güvende ve rahat hissettirmek, acil durumlarda müdahale edilebilme olasılığının arttırılması sağlanmaya çalışılmıştır.

Covid-19 vb. salgın hastalıkların yayılmasıyla birlikte hastaların hastanelere erişimi zorlaşmaktadır. Kablosuz haberleşme ile birlikte uzaktan hastanın sağlık durumunu izleme ve değerlendirme konusunun öneminin artmasıla düşük maliyetli ve kablosuz taşınabilir sağlı izleme cihazlarının gerçekleştirilmesini sağlamıştır (Türker ve Kutlu). Projemizde de günlük takibinin yapılması gereken hastalar için EKG verileri sürekli olarak uygulama aracılığıyla izlenilmektedir. Bu sayede hastanın EKG sinyalinin sürekli olarak takibi App Inventor ile telefon için oluşturduğumuz uygulama aracılığgyla izlenebilmektedir.

\section{Materyal ve Metot}

Seri haberleşme uygulamaları için kullanılan Bluetooth, Arduino ile birlikte EKG ve nabiz verilerinin tasarlanan uygulamada görüntülememize yardımcı olacaktır. EKG çipi olarak kalp hızını ölçeceğimiz, analog sinyali grafik haline dönüştürebileceğimiz veya biyopotansiyel ölçümler yapabileceğimiz AD8232 sensör kartını kullandık. AD8232 sensör kartına EKG holterlerini, EKG holterlerini de kullanıcının vücuduna belirli şekillerde yerleştirerek ölçümlerin yapılması sağlanmış olacaktır. Hasta parmağına KY-039 nabız sensörünü takarak nabzının ölçülmesi sağlanacaktır. EKG ölçümün yanında sadece nabzın ölçülmesi bile hastalık belirtisi olarak doktora bildirilebilecek ve erken teşhis ile birçok hayat kurtar1labilecektir.

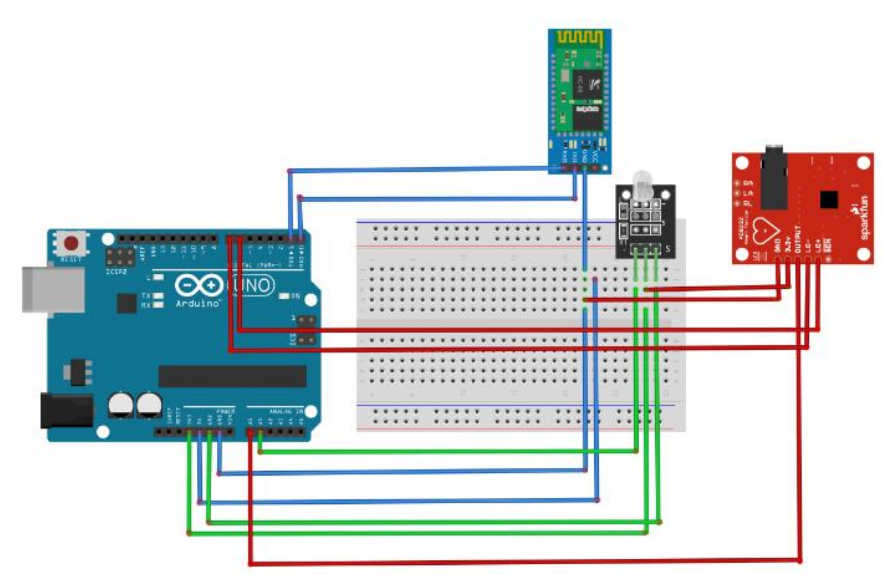

Şekil 1. Sistemin Breadboard Üzerinde Kurulumu

Devre kurulumu yapılırken kullanışlı, uygun maliyetli materyaller seçilmiştir. EKG cihazı her türlü kalp hastalıklarının tedavisinde kullanılan bir cihazdır. Maddi açıdan her insana hitap eden bu cihaz, seri üretim ile birlikte fiyatı düşücektir. Daha çok insanın kullanımına imkân sağlayacak ve erken teşhis ile birçok insanın hayatını kurtarmaya yardımcı olacaktır. Malzemeler insanların taşıyabileceği ağırlıkta seçilmiş, cihazı kullanan kişi için zorluk çıkartmayacak ve risk taşımayacak şekilde düzenlenmiştir. Cihazı taşırken kullanılan kabloların azlığı ile kullanan kişi günlük hayatında rahat edebilecek, konforlu muayene süreci geçirebilecektir. 
Tablo 1. Maliyet Değerlendirmesi

\begin{tabular}{l|c}
\hline Materyaller & Fiyat \\
\hline Arduino Uno R3 & $56,95 \mathrm{TL}$ \\
\hline $\begin{array}{l}\text { Arduino AD8232 } \\
\text { EKG Sensör Takımı }\end{array}$ & $72,88 \mathrm{TL}$ \\
\hline $\begin{array}{l}\text { HCO6 Bluetooth- } \\
\text { Serial Modül Kartı }\end{array}$ & $32,89 \mathrm{TL}$ \\
\hline Jumper Kablo & $5,60 \mathrm{TL}$ \\
\hline Breadboard & $11,78 \mathrm{TL}$ \\
\hline EKG Elektrodu & $34,96 \mathrm{TL}$ \\
\hline $\begin{array}{l}\text { Parmak Nabız Ölçer } \\
\text { Sensör }\end{array}$ & $12,18 \mathrm{TL}$ \\
\hline
\end{tabular}

Devre kurulumunun ardından çalışmanın tasarlanması için Android uygulama geliştirilmesini sağlayan MIT App Inventor programını kullandık. Arduino IDE programında yazdığımız komutlar ile Arduino üzerinde bağlantısını kurduğumuz EKG verilerini ve nabız değerlerini alıp, Android uygulama üzerinde bluetooth ile bağlatısını gerçekleştirdik. App Inventor yardımıyla oluşturduğumuz EKG cihazının kullanım uygulaması; acil durumlara karşı yardımcı olacak acil arama butonlarının kullanımı için cihazın arama bölümü, konum bilgisi için Google Maps, dosya gönderimi veya acil durum bildirimi için Whatsapp gibi uygulamalara erişimi sağlayarak tasarlanan projenin çok amaçlı kullanabilmesini sağlamaktadır.

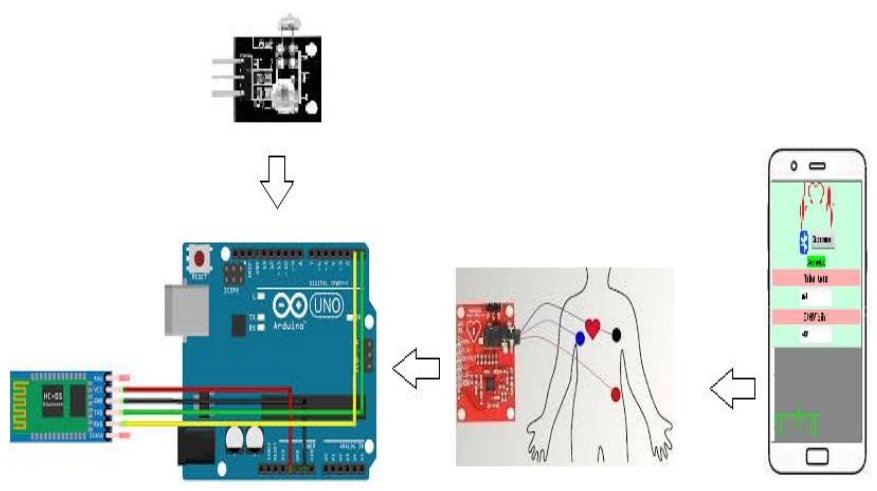

Şekil 2. Sistem Görünümü

\section{Araştırma Sonuçları ve Tartışma}

Nİ, nesnelerin birbirleriyle bilgileri paylaşarak görme, duyma, düşünme, konuşma imkânı sağlamak ve gömülü cihaz vb. teknolojilerin bir sistemden akıllı bir sisteme dönüşmesi demektir (Çakır, Aytekin ve Tüminçin, 2018). Nİ uygulama alanlarından giyilebilir teknoloji işlerimize hız kazandıracak ve daha kolay bir şekilde yerine getirebilmemizi sağlayacaktır. Sağlık alanında ise hastane hizmetlerinin eksikliği gibi yaşanan zorluklar insanları taşınabilir giyilebilir teknolojiye yönlendirmiştir (Çakır, Aytekin ve Tüminçin, 2018). Hastaneler gerek yoğunluk gerek hastalıklar açısından insanların bulunmak istemediği yerlerden biridir. Durumu ağır olmayıp kontrol altında olunması gereken ve bu yüzden hastanelerde tutulan hastalar hep bu soruna çözüm arayışında olmuşlardır. Bu konuda Nİ hayatımıza ışık tutmaktadır.
Kablosuz taşınabilir EKG cihazı, hastaların kendi yaşam çevresinde kontrollerinin yapılabilmesi için tasarlanmıştır. Tasarlanan cihazın boyutunun küçük olması, farklı ortamlara taşınmasını kolaylaştırmıştır. Sağlık personelinin ve hastanın karşılaştığ1 ortamdaki kablo karışıklığı, hareket alanının kısıtlanması, hastane ortamındaki yoğunluk, hastaların günlük hayattaki yaşamsal faaliyetlerinin engellenmesi bu cihaz sayesinde ortadan kaldırılmıştır. Doktorun ilk muayesine göre belirtilen zaman aralığı gün veya haftalarca olabilir. Covid-19 nedeniyle hastanelerde muayene olmak zorlaştı. Günlerce haftalarca muayene olması gereken biri için hastanelerdeki yatakları doldurmak yerine hastaların kendi ortamlarında muayene olup, her tür hastalığın bulunabildiği hastanelerden uzak olmak hasta açısından daha güvenilir olacak ve daha doğru sonuç elde etmeyi sağlayacaktır. Sonuçların doktora iletilip analizin yapılmasıyla, acil müdahale gereken durumlar önceden tespit edilebilecektir.

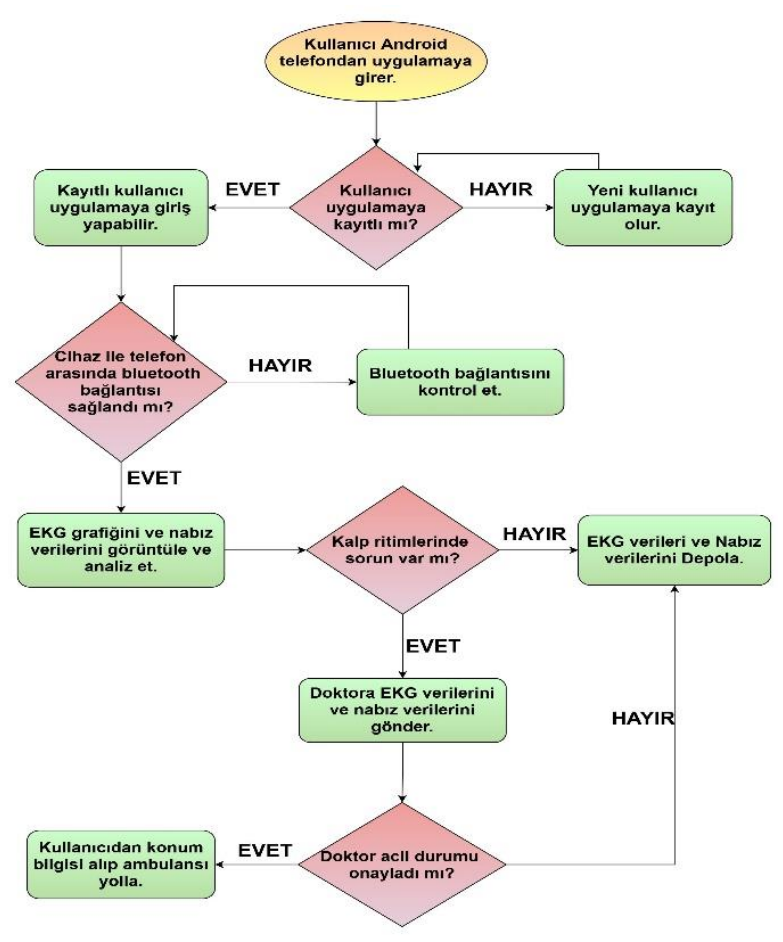

Şekil 3. Akış Diyagramı

Android ara yüzlü hazırlanan bu cihaz için öncelikle breadboard üzerinde devre kurulumu gerçekleştirilmiştir. Arduıno IDE programında HC-06 Bluetooth, AD8232 kalp hızı ölçer ve KY-039 parmak nabız ölçer sensör değerlerinin bir arada tutulması sağlanmıştır. Şekil 4'de görüldüğü gibi bluetooth yardımı ile MIT App Inventor'da tasarlanan uygulama arası bağlantı kurulmuş ve veri aktarımı sağlanmıştır. EKG verilerini sistemde gösterebilmek için kullanıcı vücuduna yerleştirilmek üzere üç elektrot kullanılmıştır. EKG verilerinin ölçülmesi büyük hassasiyet istemektedir. Devrenin doğru kurulumu ile birlikte elektrotların insan vücuduna yerleştirilmesi de dikkatli olunması gereken konulardan biridir. Nabız sensörü hastanın parmağına takılarak nabzın ölçülmesi sağlanır. Elektrotların ve nabız sensörünün vücuda bağlanması ile birlikte veriler Arduino UNO’ya aktarılır. Arduino'ya aktarılan veriler MIT App Inventor programında hazırlanan uygulamaya gönderilerek verilerin okunması sağlanır. 


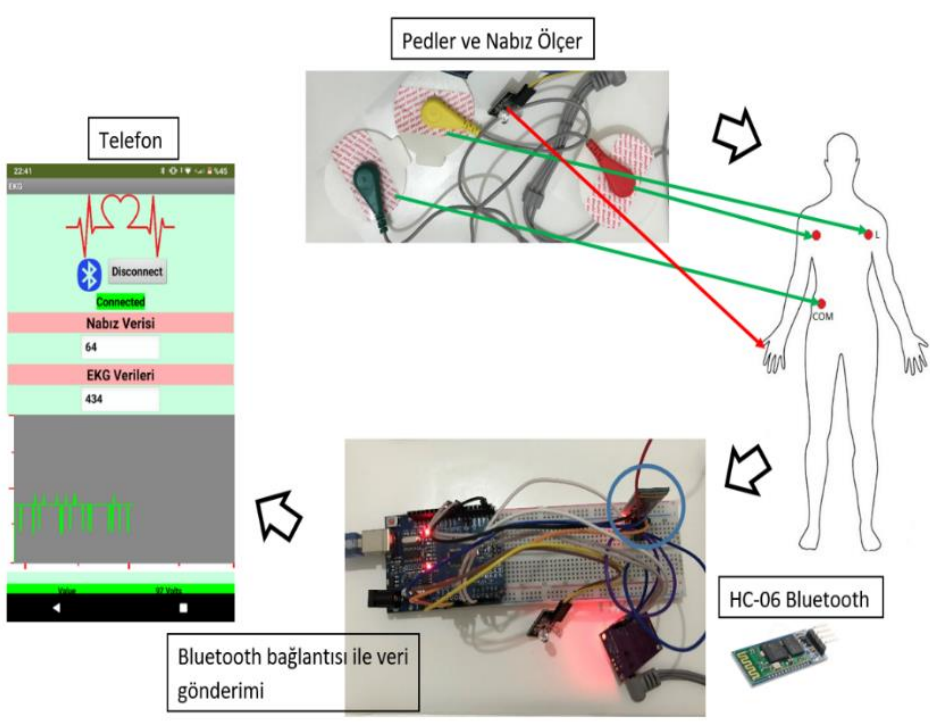

Şekil 4. Bluetooth Bağlantısı ile Android Uygulamaya Veri Gönderimi

EKG cihazları hastanın tedavisine, hastalığına bağlı olarak belli süre zarfında takılı kalabilmektedir. Hastalık belirtilerine göre değişen bu zaman aralığı doktor tarafından belirtilip, önerilen süre boyunca takılı kalmaktadır. Cihazın kullanımında dikkatli olunmalıdır. Doğru sonuç elde edebilmek için cihazın sslanmamasına, darbe almamasına dikkat edilmelidir. Okunan değerler ara yüzde grafik ile gösterilirken EKG verileri ve nabız verileri dosya içinde tutulur. Verilerin depolandığ 1 bu dosya doktora ulaştırılarak kontrollerin yapılması sağlanmaktadır. Bulut içerisinde doktorun istediği zaman aralığ 1 boyunca tutulan bu dosya doktor tarafindan analiz edilmektedir.

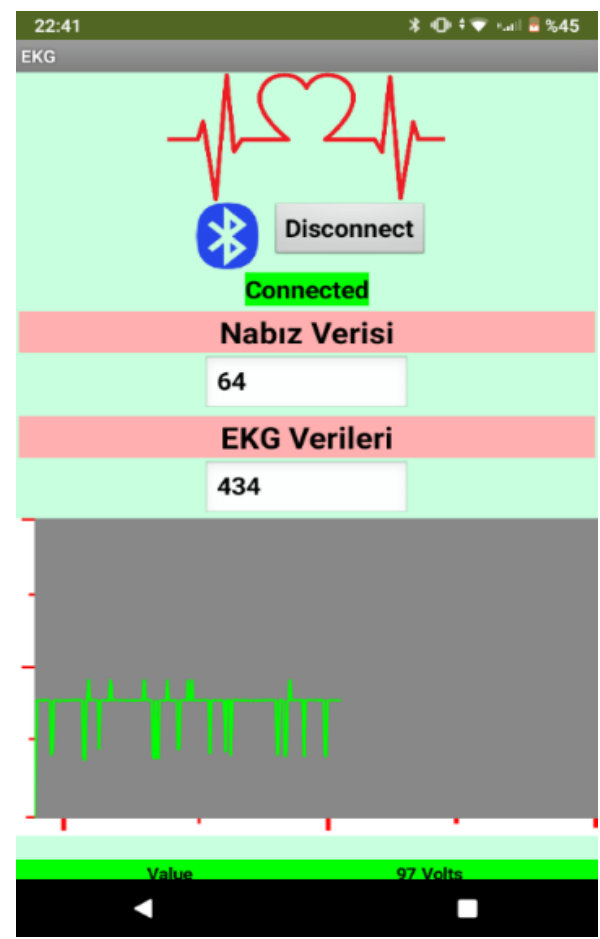

Şekil 5. EKG Ara Yüzünden Örnek

App Inventor'da tasarlanan uygulamanın EKG ara yüzü Şekil 5 'te verilmiştir. Doktor, hastanın belirtilerine göre günlerce haftalarca veya aylarca EKG cihazının taşınmasını isteyecektir.
Kablo karışıklığının engellenmesi ve materyallerin hafif olmasıyla birlikte hasta cihazı taşırken zorluk çekmeyecektir. Doktorun verdiği süre zarfında hastanın günlük aktivitelerini yaparken kullandığı EKG cihazı, bu süre boyunca kayıt yapacak ve verilerin uygulamaya iletilip dosya içerisinde tutulmasını sağlayacaktır. Veriler sayısal şekilde dosyada depolanmaktadır. Depolanan veriler hastalığın teşhisi için belli aralıklarda oluşan nabızdaki değişiklikler depolanma sayesinde günlük hayatta incelenebilmektedir. Elde edilen sayısal ve grafiksel veriler doktor muayenesi sırasında hastalığın doğru tespit edilip, doğru tedavi uygulanmasina yardımcı olacaktır. Hastane ortamında muayene edilen hastalarda görülmeyen belirtiler bu cihaz sayesinde günlük hayatta kontrol edilebilecek ve erken teşhis konulmasına yardımcı olacaktır. Bu cihaz sayesinde birçok hayat kurtulacak, yeni başlangıçlara kucak açacaktır.

Acil durumlarda hasta uygulamada yer alan konum sekmesine girerek olduğu konumu doktora gönderebilir ve acil olarak müdahale edilmesi sağlanabilmektedir. Yaşlı, engelli insanların karışık telefon içerikleri kullanma zorluğundan dolayı Şekil 6'da görüldüğü gibi uygulamada yer alan acil arama kısmının olması hastaların hayatlarının saniyeler ile kurtarılması amacını gerçekleştirmektedir. Hastane ortamı gibi bir ortam olmadan hastaların doğal yaşam yerlerinde rahat bir şekilde tedavi edilmesi hastalar açısından motive edici olacak ve acil bir durumda hemen müdahale edilecek olması hastaların kendilerini güvende hissetmelerini sağlayacaktır.

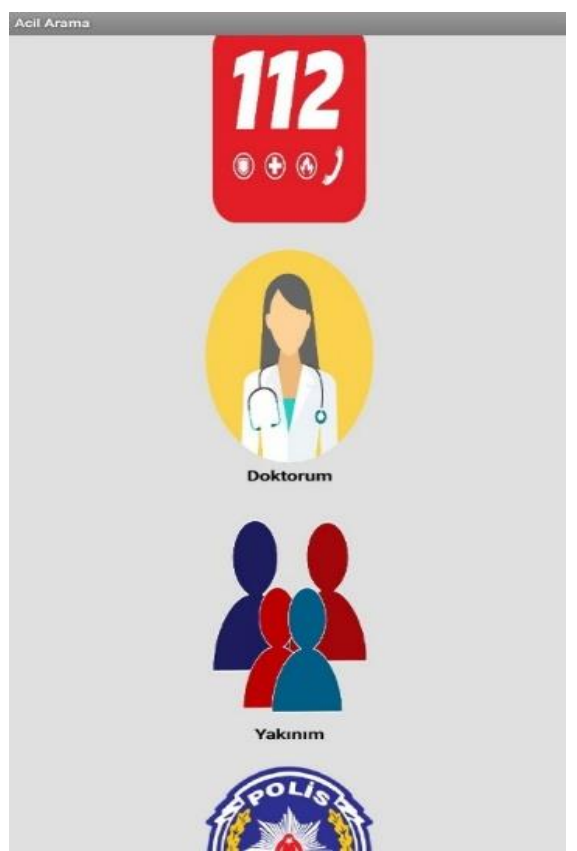

Şekil 6. Acil Arama Ara Yüzünden Örnek

\section{Sonuç}

Nİ adı altında gerçekleşen çalışmalarının sağlık alanında artmasıyla birlikte giyilebilir teknoloji yönünde de çalışmalar hızla artmaktadır. Sağlık alanında yapılan çalıșmalardan biri olan EKG cihazı, hasta konforunu sağlamak, belirtisi nadir olan hastalıkları teşhis etmek, hastaları her koşulda muayene edebilmek amacıyla geliştirilmiştir. Covid-19 nedeniyle insanlar hastaneye gitmeye çekinir hale geldi. Kolay atlatılabilen hastalıklar için hastalar hastaneye gitmeyip evlerinde kendi yöntemleriyle tedavi olurken kalp hastaları için hastaneye gitmek zorunlu oldu. Bulunduğumuz koşulların etkisiyle 
tasarladığımız EKG cihazı, evde ölçüm yapılmasının sağlanmasıyla hayatı kolaylaştırmış ve hastane ortamındaki virüse karşı önlem almamızı sağlamıştır. Doktorun tavsiye ettiği süre zarfında günlerce haftalarca vücutta takılı halde kalan bu cihaz, hastane ortamında kalmayı zorunlu hale getirmeyerek hastalara yardımcı olmuştur. Hastalar yerli olan bu cihaz ile günlük yaşantısına devam ederken aynı zamanda muayeneyi de gerçekleştirmiştir. Taşınabilir cihaz sayesinde hastalıkların kısa sürede teşhis edilmesi sağlanmış ve acil durumların oluşması azaltılmıştır. Uygulamadaki bölümler her yaş aralığındaki hastalar için kullanımı basit olacak şekilde yapılmış ve maddi açıdan her hastanın dostu olarak tasarlanmıştır. Bir saniyenin önemini bilerek hastaların hayatını kurtarmak cihazın kullanım amaçlarından biridir. Hem kontrol amaçlı hem de hayat kurtarıcı bu cihaz, hastalığın getirdiği psikolojiyi de olumlu yönde etkileyecek ve acil durumlara karşı kullanıcılara güven verecektir. Kardiyoloji doktoru veri tabanında tutulan kayıtlar ile hasta hakkında bilgiye ulaşılabilecektir. Bununla birlikte ilerde oluşabilecek hastalıklara karşı önlemler alınacak hastanın yaşam kalitesi arttırılacaktır.

\section{Teşekkür}

Çalışmamızda katkısından dolayı hocamız Sayın Doç. Dr. Nihat Daldal'a teşekkür ederiz.

\section{Kaynakça}

Akleylek, S., Kılıç, E., Söylemez, B., Aruk, T., E. ve Aksaç, C. (2020). Nesnelerin İnterneti Tabanlı Sağlık İzleme Sistemleri Üzerine Bir Çalışma. Mühendislik Bilimleri ve Tasarım Dergisi, 8(5), 80-89.

Arslan, İ., Tankut, F. (2018). Taşınabilir Elektrokardiyografi Cihazı Yapımı. Biyomedikal Mühendisliği Bölümüne Sunulan Bitirme Projesi Raporu, Lefkoşa.

Binkley P.F. (2003). Predicting The Potential of Wearable Technology. Engineering in Medivine and Biology Dergisi, 22(3), 23-27.

Can, S. (2010). EKG İşaretlerinin Cep Telefonu ile İletşlmesi. (Yayımlanmamış yüksek lisans tezi). Gazi Üniverisitesi, Bilişim Enstitüsü, Ankara.

Dinçer Ekmekci, H., Ergün, Doç. Dr. U. (2017). e-Health Kalkan ve Arduino Kullanılarak çoklu Fizyolojik İşaretlerin Bilgisayar Ortamında Görüntülenmesi. (Yayımlanmamış yüksek lisans tezi). Afyon Kocatepe Üniversitesi, Fen Bilimleri Enstitüsü, Afyon.

Göktaş, M. E. ve Yağanoğlu, M., (2020). Veri Bilimi Uygulamalarının Hastalık Teşhisinde Kullanılması: Kalp Krizi Örneği. Bilişim Sistemleri Ve Yönetim Araştırmaları Dergisi, 2(2), 26-32.

İlhan, İ. (2016). Mobil Cihaz Kontrollü EKG Holteri. Mühendislik Dergisi. 8(1), 101-110.

Kho, T. K., Besar, R., Tan, Y. S., Tee, K. H. ve Ong, K. C. (2005). Bluetooth-enabled ECG Monitoring System. IEEE Region Ten Conference, Melbourne, Qld., 1-5.

Konuk, A. (2014). EKG Sinyallerinin Bluetooth ile İletilmesi. Elektrik-Elektronik Mühendisliği Bölümüne Sunulan Bitirme Projesi Raporu, Trabzon.

Kurban, R. (2006). Kablosuz Taşınabilir Uzaktan Sağlık İzleme Sistemi: Mobil Sağlık Danışmanı. (Yayımlanmamış yüksek lisans tezi). Erciyes Üniversitesi, Fen Bilimleri Enstitüsü, Ankara.
Sönmez Çakır, Öğr. Gör. Dr. F., Aytekin, Doç. Dr. A. ve Tüminçin, Arş. Gör. F. (2018). Nesnelerin İnterneti ve Giyilebilir Teknolojiler. Sosyal Araştırmalar ve Davranış Bilimleri Dergisi. 4(5), 84-95.

Şenyer Yapıcı, İ., Işık, B. ve Uzun, R. (2018). Kablosuz Elektrokardiyogram. Düzce Üniversitesi Bilim ve Teknoloji Dergisi, 6(1), 101- 107.

Tüker, G., F. ve Kutlu, A. Giyilebilir EKG Uygulaması ve Kullanılabilir İletişim Teknolojilerinin Karşılaştırılması. Isparta.

Yalman, S., Coşkun Irmak, M. ve Haşıloğlu, A., (2015). Biyomedikal Sinyaller İzlemek İçin Bir Mobil Tabanlı Yaklaşım TipTekno'15 Tip Teknolojileri Ulusal Kongresi, 467-470, Muğla. 